\title{
Effect of wheat puroindoline alleles on functional properties of starch
}

\author{
Carla Moita Brites • Carla Alexandra Lourenço dos Santos • \\ Ana Sofia Bagulho • Maria Luísa Beirão-da-Costa
}

Received: 31 January 2007 / Revised: 12 June 2007 / Accepted: 19 June 2007 / Published online: 19 July 2007

(C) Springer-Verlag 2007

\begin{abstract}
Puroindoline $a$ and $b$ (Pina, Pinb) form the molecular basis of bread wheat grain hardness. Varieties with a softer endosperm and a wild genotype, in which both Pina and Pinb were present, seemed to produce less damaged starch flour than hard varieties, where Pin mutations occurred and changed the starch rheological properties. The functional property of starch samples extracted from wheat varieties with different Pin alleles was evaluated. Starch morphology was characterized by scanning electron microscopy and laser light scattering. Thermal properties were evaluated by differential scanning calorimetry. Amylose content, starch damage and rapid visco-analyser (RVA) parameters were also determined. Significant variations $(P<0.05)$ were identified between different $P$ in variants for the distribution pattern of starch granule volume, amylose content, starch damage, RVA viscosity breakdown and retrogradation, gelatinisation transition temperatures and enthalpies. Hard genotypes presented higher medium diameter granules and lower enthalpic values. However, the differences detected are more evident among varieties that present both Pina and Pinb, than among those presenting only one of the two $(a$ or $b)$.
\end{abstract}

C. M. Brites $(\square) \cdot$ C. A. L. d. Santos

INIAP, Estação Agronómica Nacional, DTPA, Quinta do Marques, 2784-505 Oeiras, Portugal

e-mail: carlambrites@mail.telepac.pt

A. S. Bagulho

INIAP, Estação Nacional de Melhoramento de Plantas,

Apartado 6, 7350-951 Elvas, Portugal

M. L. Beirão-da-Costa

Tecnhical University of Lisbon,

Instituto Superior de Agronomia, CEAA, DAIAT,

Tapada da Ajuda, 1349-017 Lisbon, Portugal
Keywords Wheat starch $\cdot$ Puroindolines $\cdot$ Hardness · RVA $\cdot \mathrm{DSC} \cdot \mathrm{SEM}$

\section{Introduction}

Endosperm texture is a useful characteristic to evaluate the technological ability of wheat varieties [1] affecting milling yield, flour particle size, shape and degree of starch damage. Grain texture is controlled by the hardness locus $(\mathrm{Ha})$ on the distal end of the short arm chromosome 5D [2]. The genes of three polypeptides (puroindoline- $a$, puroindoline$b$, and grain softness protein-GPS), which are components of friabilin [3, 4], have been identified as being closely linked to the $\mathrm{Ha}$ locus. Puroindolines (Pina or pina-Dla and Pinb or pinb-Dla) are thus generally considered to be genetic markers of endosperm texture [5, 6]. Soft wheats (wild type of Triticum aestivum L.) present both Pina and Pinb, whilst in hard wheats Pina is absent (null mutation, gene pina-Dla is not expressed), or several mutations are found to occur in Pinb [7-9]. In previous studies, commercial Portuguese bread wheat varieties were characterised in terms of their technological end-use, and different allelic puroindolines variants were identified $[10,11]$.

Puroindolines, which are found at the surface of starch granules, are two major isoforms (Pina and Pinb) and basic cysteine-rich proteins [12] with a molecular mass of about $13 \mathrm{kDa}$. Both may be extracted in Triton X-114 and possess a unique tryptophan-rich hydrophobic domain that is responsible for the strong affinity of puroindolines to lipids [13]. It has been suggested [4] that these lipid/protein interfaces play a major role in the texture of wheat endosperm by controlling the interactions between the starch granules and the protein matrix. Puroindoline lipid binding affinity affects flour properties, by producing stable foams on dough 
[14], and dough properties, by interfering in the formation and expansion of the gas cell [15].

Starch is the primary component of wheat flour and plays an important role in the quality of the end product. Most of the functional attributes of starch can be related to temperature-dependent interactions with water during gelatinisation, pasting and gelation (retrogradation) processes. The thermal behaviour depends on the physicochemical composition of starch, where the influence of the amylose/ amylopectin ratio, amylose-lipid complex, branch chain length or degree of polymerisation of amylopectin has been demonstrated [16-18]. Physical treatments that occurred during the milling process changed the molecular arrangement, resulting in starch damage, which influenced starch functionality [19]. Differences were also detected in the gelatinisation behaviour of granule size classes [20-23].

Inasmuch as puroindolines are closely associated with starch granules, and given their effects on grain texture and starch's influence on the quality of wheat-based end products, the aim of the present study is to contribute to the knowledge of the influence of allelic puroindoline variability on the functional properties of bread wheat starch.

\section{Materials and methods}

\section{Materials}

Twelve varieties of bread wheat (Table 1) presenting different allelic puroindoline compositions and technological properties (such as grain hardness, flour water absorption, gluten strength and dough tenacity) were selected on the basis of the results of previous studies [10, 11]. Puroindoline allelic composition was obtained by DNA isolation [24] and PCR amplification of Pina and Pinb coding regions with specific primers that identify loss of Pina [12] or point mutation in Pinb [7, 25]. A waxy wheat variety presenting quite different properties was also analysed.

\section{Methods}

Starch was extracted by a modified version of the method described by Hayakawa et al. [26]. The dough obtained from mixing purified water with flour was washed until the water came out clear. The recovered slurry was centrifuged thrice at $3,000 \mathrm{~g}$, the supernatant was discarded after each centrifugation and the starch was resuspended. The final starch slurry was then lyophilised. The apparent starch amylose content ( $\%$ as is basis) and that of starch damage were determined in duplicate samples by a colorimetric method [27] and enzymatic assay kit (Megazyme, Wicklow, Ireland), respectively, following the AACC method 76-31 [28].

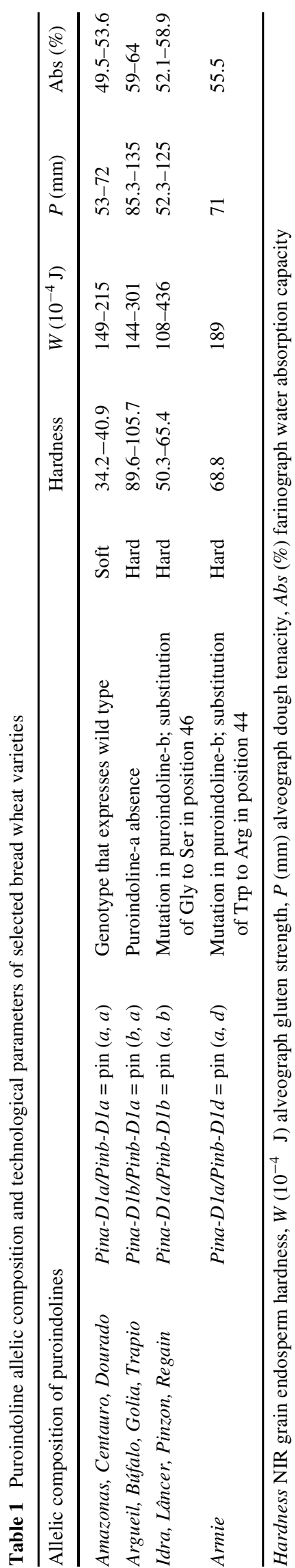


Starch granule morphology and surface were observed by scanning electron microscopy (SEM). Samples were spread on aluminium stubs, previously covered with a double-sided sticky tape. The surfaces were sputter-coated with gold. Images from starch granules were collected at $1500 \times$ amplification.

Starch granule size distribution was evaluated by laser light scattering (Mastersizer X, Malvern, UK). A polydisperse mode of analysis and a $300 \mathrm{~mm}$ lens were used. Starch powder was dispersed in isopropyl alcohol in the equipment circulation unit to attain an obscuration of 15$20 \%$. Before measuring, the sample was circulated in the equipment with mechanical agitation and ultrasound for $1 \mathrm{~min}$ to dissolve the starch clots. Measurements were taken at 2 min intervals. Size distribution was determined in four replications of duplicate samples $(n=8)$, and the results were expressed in terms of volume (\%) occupied by starch type A (diameter $>9.48 \mu \mathrm{m}$ ), type B $(5.24<\emptyset \leq 9.48 \mu \mathrm{m})$ and type $\mathrm{C}$ (diameter $\leq 5.24 \mu \mathrm{m})$ granules. In addition, a medium sphere diameter $\left(D_{(4,3)}\right)$ was calculated based on the medium volume of the three granules fractions.

The apparent viscosity of starch suspensions $(2.85 \mathrm{mg}$ starch/25 ml purified water) was analysed using a rapid visco-analyser (RVA; Newport Scientific Pvt. Ltd.) in duplicate samples. The applied trial programme was based on the method used by Batey and Curtin [29]. The evaluated parameters were: maximum viscosity and the time (min) needed to reach it; minimum (or trough) and final viscosities; breakdown (BREAK; maximum viscosity minus minimum viscosity); setback 1 (final viscosity minus maximum viscosity); and setback 2 (STB.2; final viscosity minus minimum viscosity). All the results are expressed in RVA units $(1 \mathrm{RVAU} \approx 12 \mathrm{cP})$.

Thermal properties were evaluated by DSC analysis, performed in a Shimadzu DSC 50 equipped with a TA 50 SI thermal analyser. Helium (99.95\% purity) was the purge gas and flowed at approximately $20 \mathrm{~mL} \mathrm{~min}^{-1}$. The calorimeter was calibrated according to a standard procedure laid down in the manufacturer's user manual. The DSC instrument was calibrated using indium $\left(\mathrm{mp} 156.6^{\circ} \mathrm{C}\right.$, $\Delta H_{f}=28.45 \mathrm{~J} \mathrm{~g}^{-1}$ ) and deionised water $\left(\mathrm{mp} 0{ }^{\circ} \mathrm{C}, \Delta H_{\mathrm{m}}\right.$ $333 \mathrm{~J} \mathrm{~g}^{-1}$ ). Triplicate samples of about $5.0 \pm 0.5 \mathrm{mg}$ were weighted directly in aluminium pans (inner volume $40 \mu \mathrm{L}$ ) at a water/starch ratio of 70:30 (w/w), covered and hermetically sealed into place, and allowed to equilibrate at room temperature before scanning. An empty, hermetically sealed aluminium pan was used as reference. Samples were subjected to the following heating programme: from 30 up to $100{ }^{\circ} \mathrm{C}$ at a heating rate of $20^{\circ} \mathrm{C} / \mathrm{min}$. Thermal transitions were defined in terms of onset $\left(T_{0}\right)$, peak $\left(T_{\mathrm{p}}\right)$, and endset $\left(T_{\mathrm{c}}\right)$ transition temperature. Heat of transition or enthalpy $\Delta \mathrm{H}\left(\mathrm{J} \mathrm{g}^{-1}\right)$ was evaluated from peak areas and the results were expressed per weight $(\mathrm{g})$ of sample. The manufacturer's software programme was used to analyse and plot the thermal data.

Results were subjected to variance analysis (general linear model procedure, $F$-test on type III sum of squares; [30]), which was conducted in such a way as to detect significant differences $(P<0.05)$ between puroindoline protein alleles. Significantly $(P<0.05)$ different puroindoline protein allele means were classified by Duncan's test. Linear relationships between previously determined starch and flour technological quality parameters [10] were examined by generating Pearson correlation coefficients.

\section{Results and discussion}

As observed by SEM (Fig. 1), wheat starch granules from all varieties showed typical morphological characteristics: lenticular large granules, as well as spherical small ones. No marked morphological differences were observed between the starch granules of different wheat varieties. However, the surface of starch granules from "hard" cultivars (Fig. 1a, d) seems to present more grooves than that of those from soft and waxy varieties (Fig. 1b, c, respectively).

All varieties showed a population with three typical starch granule sizes: small granules (type C); midsize granules (type B); and large granules (type A). Highly significant differences were detected between puroindoline alleles as regards mean starch granule size distribution and medium diameter $\left(D_{(4,3)}\right.$; Fig. 2 , Table 2$)$, ranging from 19.9 to $22.8 \mu \mathrm{m}$.

The histograms presented in Fig. 2a show that type A (granule with diameter $>9.48 \mu \mathrm{m}$ ) represents more than $75 \%$ of the volume in all the studied varieties. Figures ranging from 57.9 to $76.9 \%$ for granule type A population were obtained [31] in 12 soft wheat cultivars, but the cut-off points that delineate the class is $9.9 \mu \mathrm{m}$ instead of $9.48 \mu \mathrm{m}$. Soft varieties, with both puroindolines- $a$ and $-b$ [pin $(a, a)$ ], showed a significantly higher percentage of volume occupied by small (type $\mathrm{C}$ ) and medium (type B) size granules, and a significantly lower percentage occupied by large (type A) size granules than was the case in hard [pin $(a, b)$, pin $(b, a)$ and pin $(a, d)]$ wheat bread varieties.

The results also revealed a smaller medium diameter (Fig. 2d) in soft varieties (pin $(a, a)$ ) than in the hard ones. Waxy starch presented an intermediate size.

The relationship between the size distribution of starch granules and wheat texture (hardness) has not yet been clearly established by the results of other authors [32, 35]. Differences observed in the range of A, B and C sizes, classes and hardness values for the analysed cultivars may be the primary reason for the difference encountered. It should 
Fig. 1 Images of starch granules from different wheat varieties obtained by SEM. a Hard wheat Trapio; b soft wheat Centauro; $\mathbf{c}$ waxy wheat at $1,500 \times$ magnification; $\mathbf{d}$ hard wheat Trapio at 3,500 $\times$ magnification. Arrow indicates the grooves in the starch granule
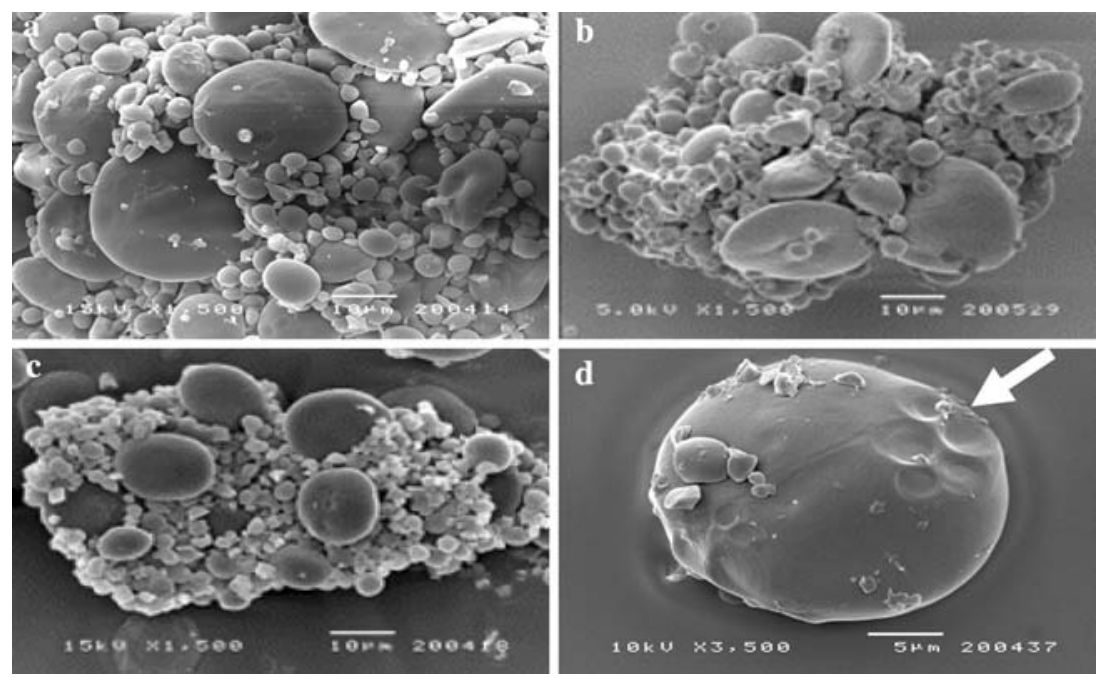

Fig. 2 Histograms representing the mean and standard deviations of $\%$ volume occupied by type $\mathrm{A}, \mathrm{B}$ and $\mathrm{C}$ granules and medium diameter type $\mathrm{D}$ starch granules $_{(4,3)}$, by allelic puroindoline and in waxy wheat. Histograms with the same letters ( $\mathrm{a}, \mathrm{b}$ or c) correspond to an absence of significantly different means at $P<0.05$. Error bar signifies variability among four replications of duplicate samples $(n=8)$ from the same genotype
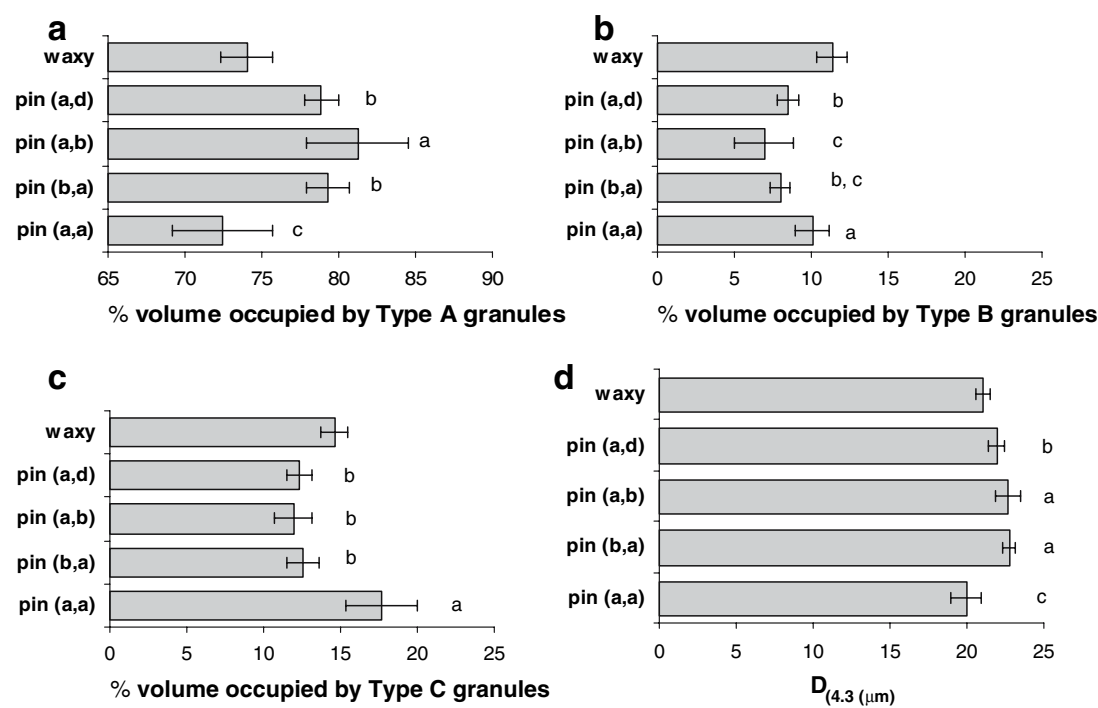

Table 2 Analysis of variance (mean squares) for starch granule size distribution of 12 bread wheats grouped in four puroindoline alleles $(n=85)$

\begin{tabular}{lccccc}
\hline Source & $d f$ & $\begin{array}{l}\text { Volume, } \\
\text { Type A }(\%)\end{array}$ & $\begin{array}{l}\text { Volume, } \\
\text { Type B }(\%)\end{array}$ & $\begin{array}{l}\text { Volume, } \\
\text { Type C }(\%)\end{array}$ & $\begin{array}{l}D_{(4,3)} \\
(\mu \mathrm{m})\end{array}$ \\
\hline Puroindolines & 3 & $375.36^{*}$ & $36.56^{*}$ & $171.60^{*}$ & $42.92^{*}$ \\
Replicates & 7 & 9.26 & 2.25 & 3.14 & 0.80 \\
Error & 85 & 6.81 & 2.59 & 2.09 & 0.54 \\
\hline
\end{tabular}

* Significant at $P=0.001$

be noted that the varieties selected in the present study show a large gap in hardness values, contrary to the majority of values presented by other authors. While in the present study NIR hardness ranges from 34.2 to 105.7 , in other studies the variation is lower [34]. Despite a large gap in hardness (16-100), Igrejas et al. [35] detected a higher number of small starch granules in hard varieties than in soft ones, in a population derived from a synthetic amphihexaploid wheat. Discrepant results can be attributed to the different nature of the germplasm, and the analytical methodologies employed are not the same. In addition, different techniques for size determination (light microscopy, Coulter Counter, laser light scattering) and comparisons using different terms of expression (volume, number, or superficial area distribution) may also significantly affect results.

Significant differences between puroindoline alleles were also found for amylose content, starch damage, RVA breakdown, RVA setback 2 and thermal DSC properties (onset and peak temperature, enthalpy or heat required to gelatinise), as shown in Table 3.

The apparent starch amylose contents of hard genotypes was found to be higher than those of the soft ones (average of $31.4 \%$ ), but only the difference for the hard allele pin ( $a$, d), with an average of $34.6 \%$, is significant (Fig. 3). As expected, significant differences between the hard and soft 
Table 3 Analysis of variance (mean squares) for amylose, starch damage, RVA breakdown and setback, DSC onset and peak temperature and enthalpy of 12 wheats grouped in four puroindoline alleles

\begin{tabular}{llllllllrr}
\hline Source & $d f$ & $\begin{array}{l}\text { Amylose } \\
(\%)\end{array}$ & $\begin{array}{l}\text { Starch } \\
\text { damage }(\%)\end{array}$ & $\begin{array}{l}\text { RVA } \\
\text { break. }\end{array}$ & $\begin{array}{l}\text { RVA } \\
\text { STB. 2 }\end{array}$ & $d f$ & $\begin{array}{l}\text { DSC } T_{0} \\
\left({ }^{\circ} \mathrm{C}\right)\end{array}$ & $\begin{array}{l}\text { DSC } T_{\mathrm{p}} \\
\left({ }^{\circ} \mathrm{C}\right)\end{array}$ & $\begin{array}{l}\text { DSC } \Delta H \\
(\mathrm{~J} / \mathrm{g})\end{array}$ \\
\hline Puroindolines & 3 & $7.78^{*}$ & $10.15^{* * *}$ & $833.56^{* *}$ & $865.12^{*}$ & 3 & $56.22^{* *}$ & $33.34^{*}$ \\
Repetitions & 1 & 0.01 & 0.05 & 53.52 & 5.79 & 2 & 1.97 & 0.49 \\
Error & 19 & 2.32 & 0.38 & 139.35 & 219.65 & 30 & 11.03 & 9.39 & 118.92 \\
\hline
\end{tabular}

*,**, *** Significant at $P=0.05, P=0.01$ and $P=0.001$, respectively

Fig. 3 Histograms representing the mean and standard deviations for RVA setback 2, breakdown, damage starch and apparent amylose content, by allelic puroindoline and in waxy wheat. Histograms with the same letters $(\mathrm{a}, \mathrm{b}$ or $\mathrm{c})$ correspond to an absence of significantly different means at $P<0.05$. Error bar signifies variability among duplicate samples from the same genotype
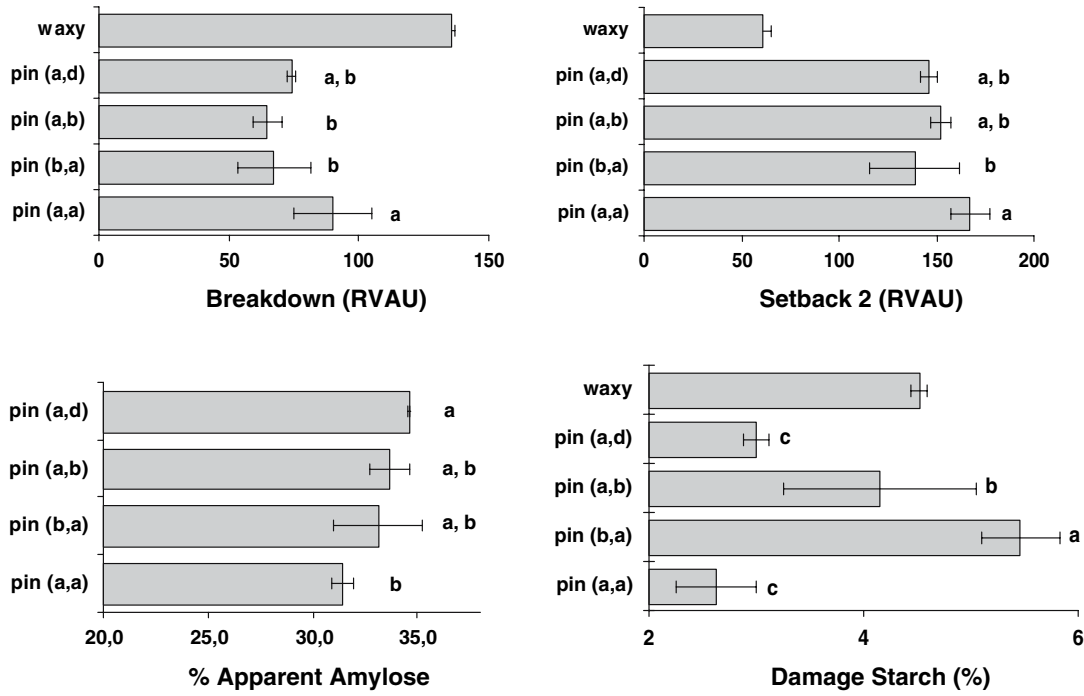

genotypes were obtained for starch damage: higher values were found in harder genotypes and the differences were more pronounced between pin $(a, a)$ and pin $(b, a)$ alleles.

The pasting viscosity profile exhibits significant differences between the soft genotype and the hard alleles pin $(b$, $a$ ) and pin $(a, b)$; when Pina is absent, the breakdown and setback are significantly lower than in the wild genotype pin $(a, a)$; the absence of Pinb has the same effect on breakdown.

Apparent amylose content is related with the maximum and minimum viscosities, thereby demonstrating a highly significantly negative correlation (result not shown) between apparent amylose and RVA breakdown.

In the present study, due to its different gelatinisation profile (as is also shown by the RVA results, Figs. 3, 4) waxy starch was used only as a reference. The expected pasting profile was obtained and reached the highest value for peak viscosity earlier (3.6 min.), with higher breakdown (135 RVU) and lower setback values (60 RVU) than the other genotypes. This is in agreement with previous findings $[36,40]$, where the rapid swelling was attributed to a high amylopectin content.

The DSC results (Fig. 5) lend further insight into the understanding of the different behaviour of hard and soft

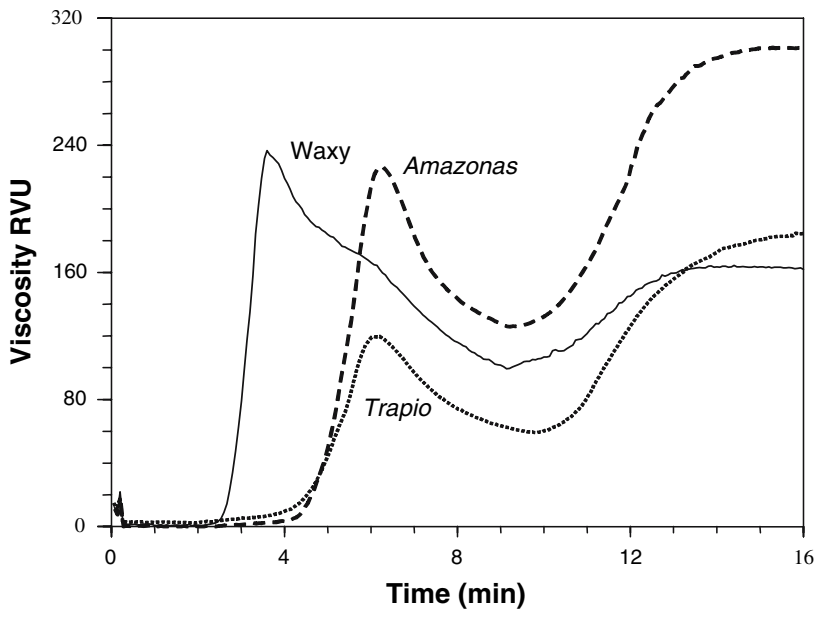

Fig. 4 RVA pasting profile of starch from waxy, soft Amazonas and hard Trapio genotypes

genotypes, which is clear from the onset gelatinisation temperatures and in which the enthalpic values constitute the most discriminating parameter.

Overall, the onset temperature varied between 41.2 and $55.4{ }^{\circ} \mathrm{C}$, and $T_{\mathrm{p}}$ from 51.1 to $65.9^{\circ} \mathrm{C}$, with significant variation between genotypes. No significant difference was 
Fig. 5 Histograms representing the mean and standard deviations of onset and peak temperatures and DSC enthalpy, by allelic puroindoline composition and for waxy wheat. Histograms with the same letters $(\mathrm{a}, \mathrm{b}$ or $\mathrm{c})$ correspond to an absence of significantly different means at $P<0.05$. Error bar signifies variability among triplicate samples from the same genotype
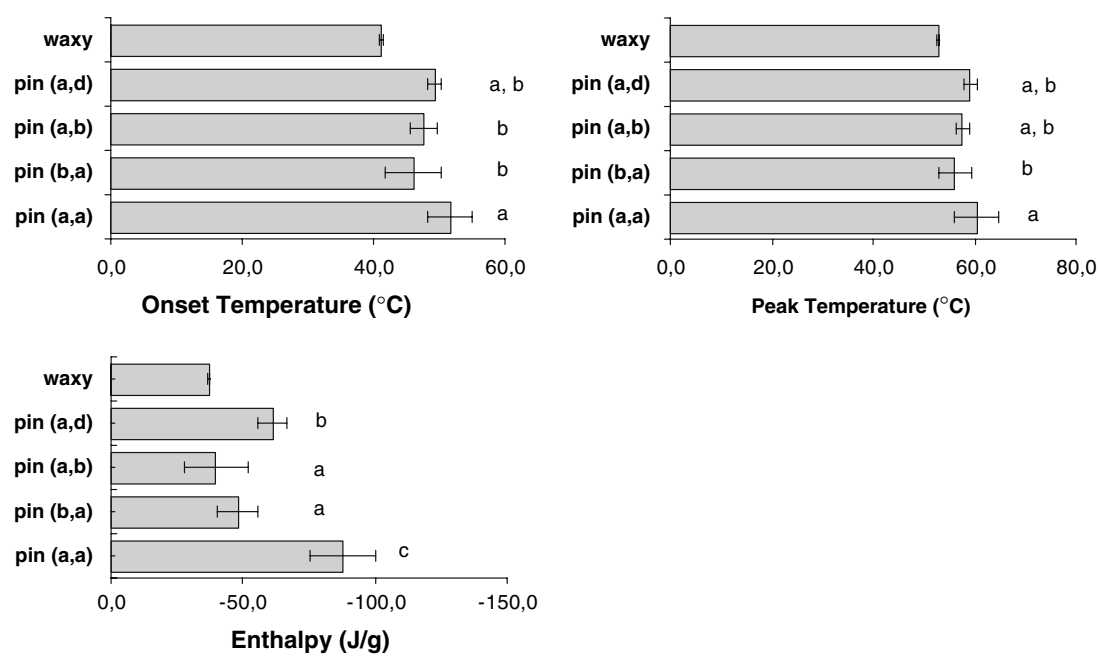

detected in the conclusion/final temperatures. In fact, when both puroindolines are present, the gelatinisation onset and peak temperatures are higher than when either one of them is missing. This aspect is more evident when looking for energy values.

Starch from soft wheat varieties required higher temperatures to start gelatinisation (onset temperature) and also more energy to complete gelatinisation than hard wheat equivalents, as evidenced by thermograms (Fig. 6) for Amazonas-pin $(a, a)$ and Trapio-pin $(b, a)$ starch.

In native starch granules, gelatinisation corresponds to granule hydration and swelling, followed by the thermal disordering of crystalline structures. It was assumed that starch granule size might influence granule hydration and swelling. The small-granule starches presented a higher ratio of surface area per unit weight of starch, and thus hydrated and swelled more efficiently than the large-granule starches. In this respect, some studies $[20,41]$ have reported higher gelatinisation enthalpies for A-type starch granules than for Btype ones, although another work [42] reports larger gelatinisation temperature ranges for B-type compared with A-type granules. In the present study, it was observed that starch

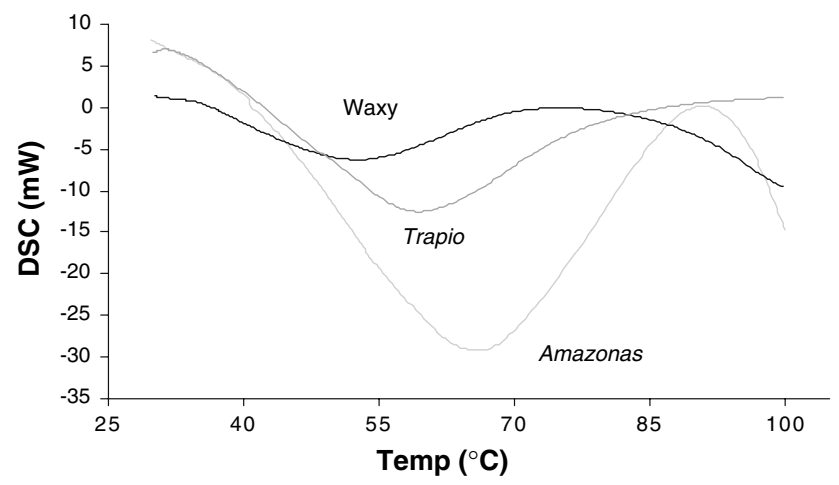

Fig. 6 DSC profile obtained for waxy Trapio-pin $(b, a)$ and Amazonas-pin $(a, a)$ starch from soft wheat varieties presented a lower starch granule medium diameter, the values for this parameter being negatively correlated to gelatinisation energy values (data not shown). In other words, the former needed higher energy values to complete the gelatinisation process than did the hard varieties. A higher peak gelatinisation temperature for small granules than for the larger fractions was also obtained $[20,23]$, a difference that was attributed to the accumulation of defects during starch biosynthesis. Large granule fractions accumulated more crystallite defects than small granules during starch deposition-a tendency that was enhanced in hard genotypes. The defects could be related to other factors like starch granule composition and degree of crystallisation [43]. The gelatinisation endotherm may also be attributed to a disordering of amylopectin crystallites [16]. However, the role of crystallinity was secondary [23], and the different thermal behaviour may well be due to the different starch amylose/amylopectin composition. Despite the influence of the amylose content, no significant difference in gelatinisation temperatures was detected between normal and waxy starch [40]. Waxy alleles of hard Búfalo, Golia and Pinzon and soft Amazonas and Centauro have been characterised $[44,45]$ and exhibit wild genotype ( $W x$ $A 1-a, W x-B 1-a, W x-C 1-a)$. Moreover, the apparent amylose content in the starch of hard genotypes [pin $(a, b)$, pin $(b, a)$ ] ranging from 33.1 to $33.7 \%$ does not significantly differ from that of soft genotypes (31.4\%), and so the differences encountered cannot be laid at the door of this parameter. Hardness proved to be negatively correlated to the surface lipid content [46]. In softer wheats containing greater lipidcomplexed amylose [34], the different behaviour detected can thus be attributed to the magnitude of the lipid-amylose complex or amylopectin-crystalline/amorphous. These characteristics affect granule starch chain organisation and the degree of crystalline organisation within the granules and inter-chain associations. On the other hand, the physical damage to starch granules during milling converts crystalline 
amylopectin into amorphous amylopectin, with the formation of some low molecular weight fragments [47]. A large proportion of very short amylopectin chains $(\mathrm{DP}<8)$ in the large granules are related to crystallite defects [23]. This phenomenon is more pronounced in hard genotypes with greater starch damage. According to Matsuki et al. [48], this is probably the reason for the lower gelatinisation temperatures and enthalpy of these genotypes. That conclusion is also supported by León et al. [19], who detected a similar influence of starch damage on the decrease in enthalpy.

Waxy starch, which has almost no amylose, displays lower transition temperatures and enthalpy than the other genotypes, and so it gelatinises easily compared to the study varieties. This probably means that in these cases, the higher amylopectin increases the disordering phenomenon, although Fujita et al. [43] obtained a higher gelatinisation temperature for a waxy genotype compared to a non-waxy type.

Differences in thermic properties between the three hard allelic variants pin $(a, d)$, pin $(a, b)$ and pin $(b, a)$ were only detected for gelatinisation enthalpy values with the higher value for allele with the Trp/Arg mutation.

Correlation coefficients between previously determined physicochemical grain and flour traits [10] and starch functionality were calculated (Table 4) in order to draw conclusions about the influence of starch on the rheological behaviour of wheat flours.

As expected, the protein content was not correlated with the starch parameters, and hardness was significantly correlated with the same parameters as those affected by puroindoline composition. Grain hardness evaluated by NIR correlated significantly $(P<0.05)$ with starch damage $(r=0.83)$, medium diameter $(r=0.66)$, RVA setback $(r=-0.62)$ and DSC transition temperatures $T_{0}(r=-0.64)$ and $T_{\mathrm{c}}(r=-0.61)$. This is corroborated by Noda et al. [49], who obtained positive correlation between the starch gelatinisation temperature and the softness of wheat. Flour sedimentation volumes evaluated by sodium dodecyl sulphate test correlated significantly $(P<0.05)$ with RVA pasting parameters (except setback).

Flour water absorption is significantly $(r=0.92$, $P<0.001)$ correlated with starch damage and negatively correlated $(r=-0.66)$ with setback 2 . Dough tenacity, as evaluated by alveograph $(P)$, is significantly negatively correlated with starch damage and DSC gelatinisation temperatures $T_{0}, T_{\mathrm{p}}$ and $T_{\mathrm{c}}$. The strong relation between grain hardness, flour water absorption, starch damage and dough tenacity was extensively reported $[1,10,19,20]$. Gluten proteins are the main compounds responsible for dough tenacity. In addition, different thermal behaviours were found [50] in gluten fractions that were isolated from one soft variety (Amazonas) and one hard variety (Sorraia). The soft variety required more energy to onset and to develop the transition than the hard variety. However, despite the importance of $P$ contribution to dough strength (as expressed by $W$ values), no relationship was found between this parameter and starch properties.

\section{Conclusions}

The analysis of medium granule diameter in 13 bread wheat variety starches clearly revealed lower values for soft genotypes than for hard genotypes.

Starch granule size distribution, starch damage, RVA breakdown, RVA setback and DSC $T_{0}, T \mathrm{p}$ and $\Delta \mathrm{H}$ parameters were affected by the presence of both puroindolines $a$ and $b$; however, more research is needed with other germplasms as isogenic lines to surpass these results in bread wheat breeding programmes. The analytical methodologies used to assess the gelatinisation phenomenon (RVA breakdown/DSC $T_{0}$; RVA Setback 2/DSC $T_{\mathrm{p}}$ ) led to similar results as regards discrimination of the puroindoline alle-

Table 4 Correlation and level of significance between some of the most relevant parameters of starch and flours analysed

\begin{tabular}{|c|c|c|c|c|c|c|}
\hline Flour starch & Protein $(\%)$ & Hard. & $\mathrm{SDS}(\mathrm{mm})$ & $\operatorname{Abs}(\%)$ & $P(\mathrm{~mm})$ & $W\left(10^{-4} \mathbf{J}\right)$ \\
\hline Damage (\%) & $-0.0594 \mathrm{~ns}$ & $0.8327 * * *$ & $-0.2533 \mathrm{~ns}$ & $0.9255^{* * *}$ & $0.8508 * * *$ & $0.4019 \mathrm{~ns}$ \\
\hline Peak. (RVA) & $0.2511 \mathrm{~ns}$ & $-0.3114 \mathrm{~ns}$ & $0.5894 *$ & $-0.3998 \mathrm{~ns}$ & $0.0101 \mathrm{~ns}$ & $0.3338 \mathrm{~ns}$ \\
\hline Trough. (RVA) & $0.2249 \mathrm{~ns}$ & $-0.2344 \mathrm{~ns}$ & $0.605 *$ & $-0.3863 \mathrm{~ns}$ & $0.1113 \mathrm{~ns}$ & $0.3539 \mathrm{~ns}$ \\
\hline End. (RVA) & $0.2984 \mathrm{~ns}$ & $-0.451 \mathrm{~ns}$ & $0.5934 *$ & $-0.562 \mathrm{~ns}$ & $-0.1125 \mathrm{~ns}$ & $0.2138 \mathrm{~ns}$ \\
\hline STB. 2 (RVA) & $0.3269 \mathrm{~ns}$ & $-0.6202 *$ & $0.4614 \mathrm{~ns}$ & -0.6601 & $-0.3574 \mathrm{~ns}$ & $0.0039 \mathrm{~ns}$ \\
\hline$T_{0}\left({ }^{\circ} \mathrm{C}\right)$ & $-0.1524 \mathrm{~ns}$ & $-0.635 *$ & $-0.08 \mathrm{~ns}$ & $-0.5586 \mathrm{~ns}$ & $-0.7709 * *$ & $-0.4649 \mathrm{~ns}$ \\
\hline$T_{\mathrm{p}}\left({ }^{\circ} \mathrm{C}\right)$ & $-0.1063 \mathrm{~ns}$ & $-0.5626 \mathrm{~ns}$ & $0.0533 \mathrm{~ns}$ & $-0.4771 \mathrm{~ns}$ & $-0.6506 *$ & $-0.2609 \mathrm{~ns}$ \\
\hline$T_{\mathrm{c}}\left({ }^{\circ} \mathrm{C}\right)$ & $-0.0805 \mathrm{~ns}$ & $-0.6095 *$ & $0.1791 \mathrm{n} . \mathrm{s}$ & $-0.5481 \mathrm{~ns}$ & $-0.6516 *$ & $-0.182 \mathrm{~ns}$ \\
\hline$\Delta H(\mathrm{~J} / \mathrm{g})$ & $-0.4559 \mathrm{~ns}$ & $-0.5382 \mathrm{~ns}$ & $-0.2925 \mathrm{~ns}$ & $0.4598 \mathrm{~ns}$ & $0.4425 \mathrm{~ns}$ & $0.1689 \mathrm{~ns}$ \\
\hline$D_{(4,3)}(\mu \mathrm{m})$ & $-0.4378 \mathrm{~ns}$ & $0.6606^{*}$ & $-0.3465 \mathrm{~ns}$ & $0.5156 \mathrm{~ns}$ & $0.5096 \mathrm{~ns}$ & $0.2188 \mathrm{~ns}$ \\
\hline
\end{tabular}

*,**,*** Significant at $P=0.05, P=0.01$ and $P=0.001$, respectively 
les-the $\Delta \mathrm{H}$ parameter being the most determinant in this respect.

The higher values for the transition temperatures and enthalpy of soft genotypes may reflect a more ordered/stable granular organisation when both puroindolines $a$ and $b$ are present in the endosperm than when one of them is absent. This is also supported by a significant negative correlation between starch thermal properties and grain hardness.

It was concluded that hard varieties require a low level of energy to onset and to develop the transition during the gelatinisation process. This aspect has important practical and useful implications for technological wheat operations, most of which-milling and the extrusion processes, for example_-are energy dependent.

Acknowledgments Thanks to Octávio Chaveiro for his help with the scanning electron microscopy, and also to Paula Batista for evaluating starch granule size distribution by laser light scattering.

\section{References}

1. Pomeranz Y, Williams RC (1990) In: Pomeranz Y (ed) Advances in cereal science and technology, vol 10. American Association of Cereal Chemists, St Paul, pp 471-548

2. Law CN, Young CF, Brown JWS, Snape JW, Worland JW (1978) In: Seed protein improvement by nuclear techniques. International Atomic Energy Agency, Vienna, pp 483-502

3. Greenwell P, Schofield JD (1986) Cereal Chem 63:379-380

4. Morris C (2002) Plant Mol Biol 48:633-647

5. Sourdille P, Perretant MR, Charmet G, Leroy P, Gautier MF, Jourdrier P, Nelson JC, Sorrels ME, Bernard M (1996) Theor Appl Gen 93:580-586

6. Gale KR (2005) J Cereal Sci 41:181-192

7. Giroux MJ, Morris CF (1997) Theor Appl Gen 95:857-864

8. Lillemo M, Morris CF (2000) Theor Appl Gen 100:1100-1107

9. Ikeda TM, Ohnishi N, Nagamine T, Oda S, Hisatomi T, Yano H (2005) J Cereal Sci 41:1-6

10. Brites C, Bagulho AS, Muacho MC, Gomes C, Antunes P, Maçãs B (2003) Melhoramento 38:107-120

11. Bagulho AS, Muacho MC, Carrillo JM, Brites C (2003) Influence of glutenin and puroindoline composition on the quality of bread wheat varieties commercialized in Portugal, In: Lafiandra D, Masci S, D’Ovidio R (eds) The gluten proteins, RSC, Cambridge, pp 113-116

12. Gautier M, Aleman M, Guirao A, Marion D, Joudrier P (1994) Plant Mol Biol 25:43-57

13. Marion D, Gautier MF, Joudrier P, Ptak M, Pezolet M, Forest E, Clark DC, Broekaert W (1994) Structure and function of wheat lipids binding proteins. In: Univ. Degli Studi Della Tuscia (ed) Wheat kernel proteins, molecular and functional aspects. Viterbo, pp 175-180

14. Dubriel L, Compoint JP, Marion D (1997) J Agr Food Chem 455:108-116

15. Igrejas G, Gaborit T, Oury F-X, Chiron H, Marion D, Branlard G (2001) J Cereal Sci 34: 37-47

16. Tester RF, Morrison WR (1990) Cereal Chem 67:551-557

17. Zeng M, Morris CF, Batty IL, Wrigley CW (1997) Cereal Chem 74:63-71
18. Sasaki T, Matsuki J (1998) Cereal Chem 75:525-529

19. León AE, Barrera GN, Pérez GT, Ribotta PD, Rosell CM (2006) Eur Food Res Technol 224:187-192

20. Peng M, Gao M, Abdel-Aal E, Hucl P, Chibbar R (1999) Cereal Chem 76:375-379

21. Peterson DG, Fulcher RG (2001) Food Res Int 34:357-363

22. Turhan M, Gunasekaran S (2002) J Food Eng 52:1-7

23. Vermeylen R, Goderis B, Reynaers H, Delcour JA (2005) Carbohydr Polym 62:170-181

24. Dellaporta SL, Wood J, Hicks JB (1983) Plant Mol. Biol Rep 1:19-21

25. Corona V, Gazza L, Zanier R, Pogna NE (2001) J Genet Breed 55:187-189

26. Hayakawa K, Tanaka K, Nakamura T, Endo S, Hoshino T (1997) Cereal Chem 74:576-580

27. International Standardization Organization (2006), ISO/DIS $6647-$ 2. Rice-determination of amylose content 2: routine method, $p 10$

28. AACC (2000) Approved methods of the AACC, 10th edn. American Association of Cereal Chemists, St Paul

29. Batey IL, Curtin BM (2000) Cereal Chem 77:754-760

30. Sas Instute Inc. (1999) SAS/STAT ${ }^{\circledR}$ User's guide-release, 8th edn. In: Sas Institute Inc. (ed) Cary, NC, p 1028

31. Raeker MÖ, Gaines CS, Finney PL, Donelson T (1998) Cereal Chem 75:721-728

32. Pitts MJ, Liao K, Glenn G (1989) Classifying wheat kernel milling performance via starch granule size. Paper 893566, American Society of Agricultural Engineers

33. Bechtel DB, Zayas I, Dempster R, Wilson JD (1993) Cereal Chem 70:238-240

34. Gaines C, Raeker M, Tille YM, Finney P, Wilson J, Bechtel D, Martin R, Seib P, Lookhart G, Donelson T (2000) Cereal Chem 77:163-168

35. Igrejas G, Faucher B, Bertrand D, Guibert D, Leroy P, Branlard G (2002) J Cereal Sci 35: 103-107

36. Ming Z, Morris CF, Batey IL, Wrigley CW (1997) Cereal Chem 74:63-71

37. Jane J, Chen YY, Lee LF, McPherson AE, Wong KS, Radosavljevic M, Kasemsuwan T (1999) Cereal Chem 76:629-637

38. Sasaki T, Yasui T, Matsuki J (2000) Cereal Chem 77:58-63

39. Abdel-Aal ES, Hucl P, Chibbar RN, Han HN, Demeke T (2002) Cereal Chem 79:458-464

40. Chakraborty M, Matkovic K, Grier DG, Jarabek EL, Berzonsky WA, McMullen MS, Doehlert DC (2004) Starch 56:339-347

41. Chiotelli E, Le Meste M (2002) Cereal Chem 79:286-293

42. Ao Z, Jane J (2007) Carbohydr Polym 67:46-55

43. Fujita S, Yamamoto H, Sugimoto Y, Morita N, Yamamori M (1998) J Cereal Sci 27:1-5

44. Brites C, Rodríguez QM, Vásquez JF, Bagulho AS, Carrillo JM (2006). Influencia del genotipo waxy y de las puroindolinas en parámetros de calidad de variedades españolas y portuguesas de trigo panadero. In: Proceedings of the Cong. Int. Ciencia y Tecnología de los Alimentos, Córdoba, p 473

45. Marcoz-Ragot C, Gateau I, Koenig J, Delaire V, Branlard G (2000) Plant Breed 119:305-309

46. Iwona K, Rotkiewicz D, Tańska M (2005) Eur Food Res Technol 220:20-24

47. Morrison WR (1995) Cereal Foods World 40:437-446

48. Matsuki J, Yasui T, Kohyama K, Sasaki T (2003) Cereal Chem 80:476-480

49. Noda T, Tohnooka T, Taya S, Suda I (2001) Cereal Chem 78:395399

50. Falcão-Rodrigues MM, Moldão-Martins M, Beirão-da-Costa ML (2005) Food Chem 93:459-465 